\title{
QUALIDADE DE VIDA DE IDOSOS COM DOENÇA RENAL CRÔNICA EM HEMODIÁLISE
}

Luana Fioravanti Roland; Universidade Federal de Santa Maria (UFSM); luanafioravanti.ufsm@gmail.com Carla Cristina Bauermann Brasil; Universidade Federal de Santa Maria (UFSM); carlacristinab@gmail.com Loiva Beatriz Dallepiane; Universidade Federal de Santa Maria (UFSM); loiva.dallepiane@hotmail.com

\section{RESUMO}

Introdução: A expectativa média de vida dos brasileiros aumentou e observa-se um crescimento no número de idosos com doença renal crônica. Objetivo: Avaliar a qualidade de vida de idosos com doença renal crônica em hemodiálise. Métodos: Trata-se de um estudo transversal com idosos que realizavam hemodiálise em uma clínica renal de referência na região central do Rio Grande do Sul. Para mensurar os indicadores de qualidade de vida relacionada à saúde (QVRS), aplicou-se o questionário Kidney Disease Quality Of Life - Short Form. O instrumento é formado por oito dimensões que avaliam a saúde geral do indivíduo e 12 dimensões específicas sobre a doença renal, sendo que os domínios variam de 0 a 100 pontos. Para a análise das pontuações no teste foi empregado o programa disponibilizado pelo KDQOL-SF ${ }_{\text {TM }}$ Working Group e dividida em duas categorias: Melhor QVRS ( $\geq 50$ pontos) e Baixa QVRS ( $<50$ pontos). O estudo foi aprovado pelo Comitê de Ética em Pesquisa da Universidade Federal de Santa Maria. Resultados: Participaram do estudo 122 idosos com média de idade de 70,31 $\pm 6,92$ anos e a maioria do sexo masculino $(59,00 \%)$. A QVRS foi melhor percebida nos subdomínios: função cognitiva $(85,03 \pm 18,94)$, suporte social $(84,84 \pm 25,44)$ e qualidade da interação social $(83,20 \pm 18,00)$. Já, a menor percepção da QVRS foi nos subdomínios: sobrecarga da doença renal $(36,42 \pm 22,07)$, funcionamento físico $(42,75 \pm 28,84)$ e saúde geral $(44,26 \pm 18,54)$. Conclusão: Foi possível observar que a hemodiálise exerce influência para baixa qualidade de vida dos idosos nas categorias avaliadas.

Palavras-chave: Insuficiência Renal; Saúde do Idoso; Diálise Renal.

Agradecimentos: À Coordenação de Aperfeiçoamento de Pessoal de Nível Superior - Brasil (CAPES) pela concessão da bolsa de estudos para realização do presente trabalho. 